\title{
Assessment of Heart Failure Patients' Interest in Mobile Health Apps for Self-Care: Survey Study
}

Albert Sohn ${ }^{1}$, BSc; William Speier ${ }^{1}$, DPhil; Esther Lan ${ }^{1}$, BSc; Kymberly Aoki ${ }^{1}$, RN; Gregg Fonarow ${ }^{2}$, MD; Michael Ong $^{1}$, MD, DPhil; Corey Arnold ${ }^{1,3}$, DPhil

${ }^{1}$ Department of Radiological Sciences, University of California, Los Angeles, Los Angeles, CA, United States

${ }^{2}$ Department of Cardiology, University of California, Los Angeles, Los Angeles, CA, United States

${ }^{3}$ Pathology \& Laboratory Medicine, University of California, Los Angeles, Los Angeles, CA, United States

\section{Corresponding Author:}

Corey Arnold, DPhil

Department of Radiological Sciences

University of California, Los Angeles

924 Westwood Blvd Ste 420

Los Angeles, CA, 90024

United States

Phone: 13107943538

Email: cwarnold@ucla.edu

\section{Abstract}

Background: Heart failure is a serious public health concern that afflicts millions of individuals in the United States. Development of behaviors that promote heart failure self-care may be imperative to reduce complications and avoid hospital re-admissions. Mobile health solutions, such as activity trackers and smartphone apps, could potentially help to promote self-care through remote tracking and issuing reminders.

Objective: The objective of this study was to ascertain heart failure patients' interest in a smartphone app to assist them in managing their treatment and symptoms and to determine factors that influence their interest in such an app.

Methods: In the clinic waiting room on the day of their outpatient clinic appointments, 50 heart failure patients participated in a self-administered survey. The survey comprised 139 questions from previously published, institutional review board-approved questionnaires. The survey measured patients' interest in and experience using technology as well as their function, heart failure symptoms, and heart failure self-care behaviors. The Minnesota Living with Heart Failure Questionnaire (MLHFQ) was among the 11 questionnaires and was used to measure the heart failure patients' health-related quality of life through patient-reported outcomes.

Results: Participants were aged 64.5 years on average, 32\% (16/50) of the participants were women, and 91\% (41/45) of the participants were determined to be New York Heart Association Class II or higher. More than 60\% (30/50) of the survey participants expressed interest in several potential features of a smartphone app designed for heart failure patients. Participant age correlated negatively with interest in tracking, tips, and reminders in multivariate regression analysis $(P<.05)$. In contrast, MLHFQ scores (worse health status) produced positive correlations with these interests $(P<.05)$.

Conclusions: The majority of heart failure patients showed interest in activity tracking, heart failure symptom management tips, and reminder features of a smartphone app. Desirable features and an understanding of factors that influence patient interest in a smartphone app for heart failure self-care may allow researchers to address common concerns and to develop apps that demonstrate the potential benefits of mobile technology.

(JMIR Cardio 2019;3(2):e14332) doi: 10.2196/14332

\section{KEYWORDS}

mHealth; patient-reported outcome; heart failure; self-care; patient monitoring 


\section{Introduction}

\section{Background}

Heart failure is a complex clinical syndrome characterized by the impairment of the heart's function to fill or eject blood [1,2]. It is a major global health problem with an estimated prevalence of 6.5 million adults in the United States [3] and 37.7 million people worldwide [4]. Every year in the United States, there are approximately 1 million new cases of heart failure and 330,000 heart failure-related deaths [3]. Projections suggest that heart failure's prevalence will increase by $46 \%$ between 2012 and 2030 [5]. Its total cost, which includes the expense of health care services, medications, and sick leave, may reach US $\$ 69.7$ billion by 2030 , a $127 \%$ increase from roughly US $\$ 30.7$ billion in 2012 [5].

Several cohort studies have indicated that the prevalence of heart failure increases significantly with age. In the Framingham Study by Ho et al [6], the prevalence was $0.8 \%$ in both men and women aged between 50 and 59 years before rising to $6.6 \%$ in men and $7.9 \%$ in women aged between 80 and 89 years. Similarly, the Rotterdam Study by Mosterd et al [7] showed a prevalence of $1 \%$ in the age group of 55 to 64 years, whereas it surpassed $10 \%$ in individuals aged 85 years or older. Much like its prevalence, incidence of heart failure is substantially higher in the elderly. In contrast to the annual incidence rates of $0.3 \%$ in men and $0.2 \%$ in women aged between 50 and 59 years, rates were $2.7 \%$ and $2.2 \%$, respectively, in those aged between 80 and 89 years [6]. The cardiovascular health study by Huffman et al [8] that focused on individuals aged 65 years or older approximated an incidence of 19.3 per 1000 person-years.

Owing to the increasing prevalence of heart failure and rising financial implications, forming efficient heart failure prevention and treatment strategies is imperative. Currently, clinicians counsel heart failure patients on evidence-based recommendations outlined in clinical practice guidelines, which include taking prescription drugs, exercising, monitoring daily weight, and restricting sodium intake [9]. However, divergence from these guidelines contributes to hospital re-admission rates that surpass $20 \%$ within the first 30 days of discharge $[10,11]$ and approach 50\% within 6 months of discharge [12], with a substantial proportion of the 30-day rehospitalizations considered preventable [13].

\section{Objectives}

As heart failure patients show poor adherence to self-care behaviors, mobile health (mHealth) has emerged as a potential solution to improve their health outcomes and quality of care. mHealth is defined as the application of mobile technology $[14,15]$, including software apps on mobile devices [16] and wireless sensors such as activity trackers [17]. These technological developments monitor activity and provide reminders of self-care behaviors and heart failure symptoms, which may be difficult for patients to ascertain [16]. Moreover, activity trackers are minimally invasive options that may also be preferable because of individuals' relatively high adherence to wearing them upon recommendation. In a previous study performed by members of our team, adherence rates for wearing activity trackers were observed to be as high as $90 \%$ [18]. The purpose of this study was to assess patient interest, specifically needs and preferences, regarding their heart failure self-care and their perceptions regarding a smartphone app integrated with home monitoring sensors. Results were analyzed to achieve the secondary end point of this study, which was to determine the factors that influence their interest.

\section{Methods}

\section{Recruitment}

From February 2018 to September 2018, study personnel collaborated with internal medicine, cardiomyopathy, and cardiology outpatient clinics to prescreen all patients diagnosed with heart failure at a university-based health system. Heart failure patients aged between 50 and 80 years were eligible to participate in this anonymous study if they were scheduled for an appointment at any of the 3 outpatient clinics. Exclusion criteria included having a cognitive (eg, dementia) disability, being unable to communicate in English, and having visual or auditory impairments to the extent that a smartphone could not be used.

Research personnel contacted potential participants over the phone, provided additional information about the study, and conducted the verbal consent process with those who were interested in participating. In the clinic waiting room, an informational sheet that described the study was given to those who consented to participate. The research team asked the participants to complete the survey before their scheduled appointment and informed them that omitting answers to any questions was permitted. Enrolled subjects received a US \$20 gift card.

Upon enrolling in the study, each participant's New York Heart Failure Association (NYHA) classification and ejection fraction (EF) was noted. The NYHA classification categorizes heart failure patients by considering their symptoms during physical activity [19]. EF is a measurement that reports the heart's degree of function by monitoring the percentage of blood leaving the left ventricle when it contracts. These data were recorded to describe the patients' heart failure according to the severity of their symptoms and limitations.

\section{Survey Questions}

The survey comprised 15 sections, all written in American English. A total of 4 sections comprised questions relating to sociodemographic information, interest in specific smartphone app features, preferences regarding specific smartphone app notifications, and experience using technology. The section pertaining to interest in specific smartphone app features for heart failure self-care management evaluated the participants' interests using a 5-point Likert scale [20]. It included questions regarding symptom tracking, tips, and reminders (Multimedia Appendix 1). Each participant's responses to questions in these groups were averaged for data analysis. The section concerning notification preferences instructed subjects to indicate how often they would like to receive reminders and information related to heart failure self-care: never, once a day, every 12 hours, every 6 hours, every 4 hours, or every 2 hours (Multimedia 
Appendix 1). To determine the participants' experience with technology, 12 yes or no questions from the Health Information National Trends Survey were asked (Multimedia Appendix 1) [21].

The remaining sections included questions regarding function, heart failure symptoms, and heart failure self-care behaviors. The participants' function and behaviors were detailed using the following institutional review board-approved questionnaires: Minnesota Living with Heart Failure Questionnaire (MLHFQ), Self-Care of Heart Failure Index (SCHFI), shortened version of the Seattle Angina Questionnaire (SAQ-7), shortened version of the Kansas City Cardiomyopathy Questionnaire (KCCQ-12), Patient-Reported Outcomes Measurement Information System (PROMIS) Global Health, and PROMIS Physical Function short form (SF). Symptoms were measured using a variety of PROMIS questionnaires: Fatigue SF, Anxiety SF, Depression SF, Sleep Disturbance SF, and Social Isolation SF. Scores from these questionnaires represented patient-reported outcomes (PROs), which are reports of a patient's health status directly from the patient. PROs were used to describe the study population because patients were recruited irrespective of the time of their heart failure diagnoses. Along with participants' demographics, MLHFQ scores were of particular interest as they represented heart failure patients' health-related quality of life (HRQOL), which is a factor that might influence their interests in features of a smartphone app.

\section{Scoring}

The 21-item MLHFQ is among the most widely used patient-oriented measurements of HRQOL [22]. It accounted for 3 ways heart failure affected the participants: physical, emotional, and socioeconomic. Although there is no scale for the socioeconomic score, physical (0-40) and emotional (0-25) scores were calculated by summation of corresponding responses. Lower scores signified better HRQOL, whereas higher scores signified worse HRQOL in regard to physical and emotional well-being [22]. A total score was also generated by addition of all 21 responses, resulting in a possible range of 0 to 105 . Scores were classified as good $(<24)$, moderate $(24-45)$, and poor (>45) HRQOL [22].

SCHFI is a 22-item questionnaire that assesses the patient's ability to care for their heart failure via 3 subscales: maintenance, management, and confidence [23]. For each subscale, the raw score was calculated by summation of corresponding responses. Raw scores were then standardized to a 0 to 100 range, with higher scores indicating better self-care. Management scores were calculated only if heart failure patients acknowledged having trouble breathing or ankle swelling within the past month of taking this survey. For all sections of the SCHFI, scores $\geq 70$ proposed adequate self-care [23].

The SAQ-7 and KCCQ-12 also assessed the HRQOL of patients with respect to angina and heart failure, respectively [24,25]. Scores for both questionnaires were calculated by summation of all 7 and 12 responses, respectively, and by standardization of those values to a 0 to 100 range. Scores were classified as poor (0-24), fair (25-49), good (50-74), and excellent (75-100) HRQOL [24,25].

PROMIS questionnaires are publicly available individual-centered measures of PROs [26,27]. The aforementioned physical and mental health questionnaires were administered to heart failure patients to assess their function and symptoms. Raw scores were computed by addition of all corresponding responses and conversion of those values to $t$ scores, which were standardized scores set to a mean of 50 and a standard deviation of 10 [26,27]. Function scores $\geq 40$ were normal, whereas scores $<40$ denoted moderate to severe adverse health effects. Symptom scores $\leq 60$ were normal, whereas scores $>60$ represented moderate to severe adverse health effects [26,27].

\section{Statistical Analysis}

Before calculating raw scores, questionnaires were examined for completion. For any missing items, the mean of the participant's responses from the same questionnaire was substituted [28]. The cohort was characterized using proportions, means, SDs, medians, and interquartile ranges (IQRs). Summaries of responses and scores, if applicable, for each questionnaire were reported. Linear regression analyses, including multivariate regression analysis, were performed with the participants' age and MLHFQ scores as the independent variables to quantify the linear relationships with their interest in smartphone app features. For all analyses, a significance level of .05 , which corresponded to a $95 \% \mathrm{CI}$, was used to determine statistical significance.

\section{Results}

\section{Demographics}

Over the 7-month period, a total of 95 eligible heart failure patients were contacted. Of the 95 qualified patients, 50 consented to participate in this study (Table 1). However, 1 participant only completed the demographics section of the survey.

The participants' mean age was 64.5 years (SD 8.3; range 50-78). Most participants were men (34/50, 68\%), of non-Hispanic or non-Spanish origin $(40 / 49,82 \%)$, and white $(32 / 48,67 \%)$. Of the participants, 38\% (19/50) had received a bachelor's degree or higher, whereas for $18 \%$ (9/50), a high school degree was their highest level of education. As for annual household income, the proportions of individuals whose families earned less than US $\$ 50,000(23 / 50,46 \%)$ and more than US $\$ 50,000$ (27/50 54\%) were fairly similar. Although 91\% (31/45) of the participants were determined to be NYHA Class II or higher, $62 \%(31 / 50)$ had EFs less than 50\%. Neither NYHA class nor EF produced statistically significant associations with their interests in potential features of a smartphone app. 
Table 1. Demographics of study population.

\begin{tabular}{|c|c|}
\hline Characteristic & Value \\
\hline Age (years; $\mathrm{n}=50$ ), mean $(\mathrm{SD})$ & $64.5(8.3)$ \\
\hline \multicolumn{2}{|l|}{$\operatorname{Sex}(n=50), n(\%)$} \\
\hline Male & $34(68)$ \\
\hline Female & $16(32)$ \\
\hline \multicolumn{2}{|l|}{ Hispanic or Spanish origin $(n=49), n(\%)$} \\
\hline No & $40(82)$ \\
\hline Yes & $9(18)$ \\
\hline \multicolumn{2}{|l|}{ Race or ethnicity $(n=48), n(\%)$} \\
\hline White & $32(67)$ \\
\hline Black or African American & $11(23)$ \\
\hline Asian & $5(10)$ \\
\hline American Indian or American Native & $0(0)$ \\
\hline Native Hawaiian or other Pacific Islander & $0(0)$ \\
\hline \multicolumn{2}{|l|}{ Education $(\mathrm{n}=\mathbf{5 0}), \mathrm{n}(\%)$} \\
\hline High school & $9(18)$ \\
\hline Some college, associate degree, or trade school & $22(44)$ \\
\hline Bachelor's degree & $10(20)$ \\
\hline Master's degree or above & $9(18)$ \\
\hline \multicolumn{2}{|l|}{ Annual income (US \$; n=50), n (\%) } \\
\hline $0-25,000$ & $15(30)$ \\
\hline $25,001-50,000$ & $8(16)$ \\
\hline $50,001-75,000$ & $8(16)$ \\
\hline$\geq 75,001$ & $19(38)$ \\
\hline \multicolumn{2}{|l|}{ New York Heart Association class $(n=45), n(\%)$} \\
\hline I & $4(9)$ \\
\hline II & $26(58)$ \\
\hline III & $15(33)$ \\
\hline IV & $0(0)$ \\
\hline \multicolumn{2}{|l|}{ Ejection fraction $(n=50), n(\%)$} \\
\hline$\leq 40 \%$ & $28(56)$ \\
\hline $41 \%-49 \%$ & $3(6)$ \\
\hline$\geq 50 \%$ & $19(38)$ \\
\hline
\end{tabular}

\section{App Interest}

More than $60 \%$ of the participants were somewhat interested or very interested in a smartphone app that provides information related to symptoms (identification $31 / 48,65 \%$, and tips 35/48, $73 \%$ ), medication or treatment (side effects 33/48, 69\%), activity (steps 33/48,69\%, and exercise 31/48, 65\%), and sleep (patterns $32 / 46,67 \%$, and tips $31 / 47$, 66\%; Table 2). On the other hand, more than a quarter of the participants expressed little to no interest in documenting their mood $(17 / 48,35 \%)$ or receiving tips to improve their mood $(14 / 48,29 \%)$. Moreover, 30 participants answered somewhat interested or very interested for both symptom-related statements (Multimedia Appendix 2). Of those 30 participants, $28(28 / 30,93 \%)$ owned a smartphone and $10(10 / 30,33 \%)$ owned an activity tracker or a smartwatch. Of the 28 participants who expressed interest (somewhat interested or very interested) in both activity-related statements, $26(26 / 28,93 \%)$ owned a smartphone and $11(11 / 28$, $39 \%$ ) owned an activity tracker or a smartwatch. There were 27 participants who showed interest in both items regarding sleep. Of these, $24(24 / 27,89 \%)$ owned a smartphone and 11 $(11 / 27,41 \%)$ owned an activity tracker or a smartwatch. 
Table 2. Patients' answers to the Heart Failure Self-Care Management Application Interest questionnaire.

\begin{tabular}{|c|c|c|c|c|c|c|}
\hline Statement & $\mathrm{n}$ & $\begin{array}{l}\text { No interest, } \\
\mathrm{n}(\%)\end{array}$ & $\begin{array}{l}\text { Not very interested, } \\
\mathrm{n}(\%)\end{array}$ & $\begin{array}{l}\text { Neutral, } \\
\mathrm{n}(\%)\end{array}$ & $\begin{array}{l}\text { Somewhat interested, } \\
\mathrm{n}(\%)\end{array}$ & $\begin{array}{l}\text { Very interested, } \\
\mathrm{n}(\%)\end{array}$ \\
\hline $\begin{array}{l}\text { Symptom identification, such as noticing swelling } \\
\text { in your ankles or legs }\end{array}$ & 48 & $7(15)$ & $2(4)$ & $8(17)$ & $11(23)$ & $20(42)$ \\
\hline Providing symptom management tips & 48 & $7(15)$ & $1(2)$ & $5(10)$ & $13(27)$ & $22(46)$ \\
\hline Providing medication reminders & 48 & $9(19)$ & $4(8)$ & $9(19)$ & $9(19)$ & $17(35)$ \\
\hline $\begin{array}{l}\text { Documenting when you experience side effects from } \\
\text { medication or treatment }\end{array}$ & 48 & $5(10)$ & $2(4)$ & $8(17)$ & $10(21)$ & $23(48)$ \\
\hline $\begin{array}{l}\text { Documenting your level of activity or number of } \\
\text { steps }\end{array}$ & 48 & $6(13)$ & $4(8)$ & $5(10)$ & $9(19)$ & $24(50)$ \\
\hline Providing reminders to exercise & 48 & $7(15)$ & $2(4)$ & $8(17)$ & $10(21)$ & $21(44)$ \\
\hline Documenting your sleep patterns & 46 & $5(11)$ & $3(7)$ & $6(13)$ & $10(22)$ & $22(48)$ \\
\hline Providing tips to get better sleep & 47 & $6(13)$ & $4(9)$ & $6(13)$ & $6(13)$ & $25(53)$ \\
\hline Documenting your mood & 48 & $9(19)$ & $8(17)$ & $8(17)$ & $7(15)$ & $16(33)$ \\
\hline Providing tips to improve your mood & 48 & $9(19)$ & $5(10)$ & $10(21)$ & $8(17)$ & $16(33)$ \\
\hline
\end{tabular}

\section{Reminders}

Between $80 \%$ and $90 \%$ of the participants indicated their desire to receive reminders at least once per day for all but medication reminders, which was $71 \%$ (34/48; Table 3$)$. Once a day was the most popular response for the other 5 features. The proportion exceeded $50 \%$ for symptom management tips (27/49, $55 \%)$, activity or steps $(25 / 49,51 \%)$, exercise reminders $(27 / 49$, $55 \%)$, and sleep tips $(29 / 49,59 \%)$.

\section{Access to Technology}

The majority of participants had access to technology. Only 24 $(24 / 49,49 \%)$ participants owned a tablet, and $44(44 / 49,90 \%)$ participants owned a smartphone (Table 4). In addition, high proportions of participants had access to the internet through a cellular network $(41 / 49,84 \%)$ or a wireless network $(43 / 49$, $88 \%)$. Most participants also had experience using their smartphone (42/44 smartphone owners, $96 \%$ ) and accessing the internet or their email account(s) $(44 / 49,90 \%)$. Fewer patients had activity trackers and smartwatches as only $14 / 49(29 \%)$ participants owned one and 9/14 (64\%) participants used it regularly. Ownership of an activity tracker or smartwatch was not related to income, as half of them earned a household income that surpassed US \$75,001 annually.

Table 3. Patients' answers to Heart Failure Self-Care Management Application Engagement questionnaire.

\begin{tabular}{|c|c|c|c|c|c|c|c|}
\hline Statement & $\mathrm{n}$ & $\begin{array}{l}\text { Never, } \\
\mathrm{n}(\%)\end{array}$ & $\begin{array}{l}\text { Once a day, } \\
\mathrm{n}(\%)\end{array}$ & $\begin{array}{l}\text { Every } 12 \text { hours, } \\
\text { n }(\%)\end{array}$ & $\begin{array}{l}\text { Every } 6 \text { hours, } \\
\mathrm{n}(\%)\end{array}$ & $\begin{array}{l}\text { Every } 4 \text { hours, } \\
\mathrm{n}(\%)\end{array}$ & $\begin{array}{l}\text { Every } 2 \text { hours, } \\
\mathrm{n}(\%)\end{array}$ \\
\hline Notify you of symptoms & 49 & $9(18)$ & $20(41)$ & $8(16)$ & $3(6)$ & $4(8)$ & $5(10)$ \\
\hline Provide you with symptom management tips & 49 & $6(12)$ & $27(55)$ & $9(18)$ & $1(2)$ & $3(6)$ & $3(6)$ \\
\hline Provide you with medication reminders & 48 & $14(29)$ & $12(25)$ & $9(19)$ & $4(8)$ & $3(6)$ & $6(12)$ \\
\hline $\begin{array}{l}\text { Provide you with your level of activity/number } \\
\text { of steps }\end{array}$ & 49 & $5(10)$ & $25(51)$ & $3(6)$ & $4(8)$ & $6(12)$ & $6(12)$ \\
\hline Provide you with exercise reminders & 49 & $5(10)$ & $27(55)$ & $5(10)$ & $3(6)$ & $5(10)$ & $4(8)$ \\
\hline Provide you with sleep tips & 49 & $8(16)$ & $29(59)$ & $6(12)$ & $2(4)$ & $0(0)$ & $4(8)$ \\
\hline
\end{tabular}


Table 4. Patient answers to Health Information Nation Trends Survey.

\begin{tabular}{|c|c|c|c|}
\hline Question & $\mathrm{n}$ & No, n $(\%)$ & Yes, $\mathrm{n}(\%)$ \\
\hline Do you ever access the internet or World Wide Web or send and receive email? & 49 & $5(10)$ & $44(90)$ \\
\hline When you use the internet, do you ever access it through a regular dial-up telephone line? & 49 & $48(98)$ & $1(2)$ \\
\hline $\begin{array}{l}\text { When you use the internet, do you ever access it through broadband such as digital subscriber line, cable, or } \\
\text { fiber optic service? }\end{array}$ & 49 & $15(31)$ & $34(69)$ \\
\hline $\begin{array}{l}\text { When you use the internet, do you ever access it through a cellular network (ie, phone and third- or fourth- } \\
\text { generation cellular network technology)? }\end{array}$ & 49 & $8(16)$ & $41(84)$ \\
\hline When you use the internet, do you ever access it through a wireless network (wireless fidelity)? & 49 & $6(12)$ & $43(88)$ \\
\hline Do you own a tablet? & 49 & $25(51)$ & $24(49)$ \\
\hline Do you own a smartphone? & 49 & $5(10)$ & $44(90)$ \\
\hline If so, do you use your smartphone at least once daily? & 43 & $1(2)$ & $42(97)$ \\
\hline Do you own a cell phone? (skip if yes answer to smartphone) & 5 & $1(20)$ & $4(80)$ \\
\hline If so, are you comfortable using the cell phone? & 4 & $1(25)$ & $3(75)$ \\
\hline Do you own an activity tracker/smartwatch? & 49 & $35(71)$ & $14(29)$ \\
\hline If so, do you wear it daily? & 14 & $5(36)$ & $9(64)$ \\
\hline
\end{tabular}

\section{Patient-Reported Outcomes}

The median MLHFQ score was 52 (IQR 24-75; Table 5), which corresponded to a poor HRQOL for the average participant. On the other hand, SAQ (median 68, IQR 55-84) and KCCQ (median 61, IQR 47-80) median scores suggested a good HRQOL in relation to angina and heart failure, respectively. The median SCHFI maintenance (median 70, IQR 60-81) and SCHFI confidence (median 72, IQR 50-83) scores revealed adequate ability to perform maintenance behaviors and adequate confidence level for the average participant. Of the 49 participants, 28 (57\%) indicated recent breathing complication or ankle swelling (Table 5), which qualified them to complete the management section of the SCHFI questionnaire. Similar to the other section scores, the median SCHFI management score (median 70, IQR 50-85) indicated adequate ability to manage heart failure. Median scores for all PROMIS questionnaires were within the normal range, except for Physical Function SF (median 38, IQR 34-43), which denoted moderate adverse health implications.
In the Heart Failure Self-Care Management Application Interest questionnaire, 67\% (32/48) said they were interested in tracking, whereas $65 \%$ (31/48) said they were interested in tips and 73\% $(35 / 48)$ said they were interested in reminders (Table 2). Age correlated significantly with interest in each of the 3 features of the smartphone app $(P=.001, P=.002$, and $P=.001$, respectively). In contrast to age, MLHFQ scores (Table 5) generated positive correlations with their interests. These correlations were also statistically significant $(P=.003, P<.001$, and $P=.004$, respectively). Similarly, when multivariate regression analyses were performed with age and MLHFQ scores, they generated negative coefficients for age and positive coefficients for MLHFQ scores. Moreover, both identifiers achieved statistically significant results with tracking $(P=.007$ and .02, respectively), tips ( $P=.01$ and .002 , respectively), and reminders $(P=.007$ and .02 , respectively).

No relationship between age and frequency of the 6 different reminders (Table 3) was statistically significant: symptoms, symptom management tips, medication reminders, activity/steps, exercise reminders, and sleep tips $(P=.09, P=.26, P=.09, P=.09$, $P=.13$, and $P=.40$, respectively). 
Table 5. Patient-reported outcomes.

\begin{tabular}{|c|c|c|}
\hline Questionnaire & $\mathrm{n}$ & Median score (IQR) \\
\hline \multicolumn{3}{|c|}{ Minnesota Living with Heart Failure Questionnaire } \\
\hline Physical score & 49 & $19(12-32)$ \\
\hline Emotional score & 48 & $10(2-20)$ \\
\hline Total score & 49 & $52(24-75)$ \\
\hline \multicolumn{3}{|l|}{ Self-Care of Heart Failure Index } \\
\hline Maintenance & 49 & $70(60-81)$ \\
\hline Management & 28 & $70(50-85)$ \\
\hline Confidence & 49 & $72(50-83)$ \\
\hline Seattle Angina Questionnaire & 49 & $68(55-84)$ \\
\hline Kansas City Cardiomyopathy Questionnaire & 49 & $61(47-80)$ \\
\hline \multicolumn{3}{|l|}{ PROMIS $^{\text {a }}$ Global Health } \\
\hline Physical & 49 & $42(35-51)$ \\
\hline Mental & 49 & $48(44-51)$ \\
\hline PROMIS Physical Function & 49 & $38(34-43)$ \\
\hline PROMIS Fatigue & 49 & $57(46-63)$ \\
\hline PROMIS Anxiety & 49 & $54(39-61)$ \\
\hline PROMIS Depression & 49 & $52(41-61)$ \\
\hline PROMIS Sleep Disturbance & 49 & $52(46-60)$ \\
\hline PROMIS Social Isolation & 49 & $40(35-50)$ \\
\hline
\end{tabular}

apROMIS: Patient-Reported Outcomes Measurement Information System.

\section{Discussion}

\section{Principal Findings}

The results indicate that 38 out of 48 survey participants (79\%) were interested in at least one of the following features of a smartphone app to assist their heart failure management: symptoms, medication or treatment side effects, activity/steps, and sleep. Consequently, this study suggests the prospect of heart failure patients utilizing a smartphone app to self-monitor their condition while also receiving tips and reminders related to heart failure. Access to and experience with technology should not pose major concerns to its potential, as 43 out of 49 participants $(88 \%)$ owned a smartphone and had access to the internet.

MLHFQ score and age were 2 factors that correlated the participants' degree of interest. Their responses to questions in this survey and subsequent scores imply that many experienced adverse health outcomes because of their heart failure. The statistically significant positive correlations between their MLHFQ score and interest in tracking, tips, and reminders show that heart failure patients with lower HRQOL express greater interest in a smartphone app for heart failure than those with higher HRQOL. As the MLHFQ is reliable and sensitive to differences in symptom severity [29], heart failure patients with lower MLHFQ scores are likely more prominently afflicted by heart failure. Therefore, their interest in receiving heart failure-related information and reminders may suggest a greater likelihood of utilizing it as an individual-tailored intervention.

Analysis of age was a key aspect of this study because both prevalence and incidence of heart failure increase with age [6,7]. Accordingly, older heart failure patients are the primary target population for any intervention. In contrast to the increase of their interests with MLHFQ score, heart failure patients' interest significantly decreased with age. This result is consistent with and can be explained by previous studies that examined adults' technology usage and attitudes. In those studies, older adults acknowledged the benefits of technological advances but expressed several issues with technology, such as lack of security and reliability as well as inconvenience [30,31]. In addition, they identified low self-efficacy, high anxiety, and increased efforts as reasons for their reluctance to adopt technology [32,33]. As a result, their unfavorable outlook on technology poses a challenge to the prospect of implementing the smartphone app as an intervention. Providing incentives or alternatives, however, could address this challenge for those who may not be interested in mHealth apps.

Questionnaire scores from this survey revealed unexpected results. Both the MLHFQ and KCCQ were intended to quantify patients' HRQOL with respect to their heart failure but revealed contrasting results with statistical significance $(P<.001)$. The MLHFQ generated a median score that corresponded to poor HRQOL, whereas the KCCQ produced a median score that suggested good HRQOL. This discrepancy may be because of the fact that questions in the KCCQ examined a much shorter 
time frame ( 2 weeks) than those in the MLHFQ (4 weeks). Furthermore, the KCCQ is primarily concerned with 2 symptoms of heart failure, shortness of breath and fatigue, whereas the MLHFQ is more general. The scores from questionnaires regarding behavior and function produced mixed results, whereas all those regarding symptoms generated scores that fell within the normal range (Table 5). This outcome suggests that the mental health conditions of the participants were in favorable states despite their adverse health effects from heart failure. This finding appears to not align with a previous study that found heart failure patients have higher levels of anxiety than healthy adults, which leads to decreased treatment adherence [34]. The normal mental health of the participants may have influenced their interests in the smartphone app as a self-care strategy.

\section{Limitations and Future Directions}

This study was confined to patients from a university-based health system and was limited to those aged between 50 and 80 years. The study population was relatively well educated, which might limit the generalization of our results, although we note that we did not observe any statistically significant correlations across the observed education levels with other variables. There was greater representation of male $(34 / 50,68 \%)$ and white $(32 / 48,67 \%)$ patients in the study cohort (Table 1$)$, which might have generated results that are not applicable to the general population with heart failure. A reason for the disproportionate representation is that this study was limited to English language speakers. Literacy in English was necessary to understand the directions and questions because there was only an English version of the survey. Future study will include translation of this survey into other languages, particularly Spanish. In regard to the results, the statistically significant correlations do not indicate causation. Self-reporting of interest in mHealth may not translate to actual use, adherence, or persistence. Prospective testing of mobile technology apps will be needed along with evaluation of their effectiveness, safety, and value.

\section{Conclusions}

This study provides new information on the features that heart failure patients want from a smartphone app to assist them in managing their health. To better contextualize the desired information and features, we sought to correlate survey responses, disease state, and demographics. On the basis of our results, we propose that a smartphone app may be a viable minimally invasive alternative intervention for monitoring heart failure patients because of the generally positive reception, although we note that data in this study were collected from a single site. Participants were interested in all 3 features of the proposed smartphone app-tracking, tips, and reminders. As these are common features of activity trackers and smartwatches, they, along with a smartphone app, may be potential solutions for heart failure patients' self-care needs. Age and MLHFQ scores may be useful predictors in determining whether an heart failure patient is interested in a smartphone app for self-care. These findings suggest that certain populations may be more inclined to utilize mobile technology to manage their treatment and symptoms. We suggest that future mHealth-driven interventions that feature a smartphone app consider first soliciting feedback from their targeted population to better understand patient perspectives on how such technology can be designed to maximize impact. We suggest that this study is a step in this direction.

\section{Acknowledgments}

This study was supported by the National Institutes of Health National Heart, Lung, and Blood Institute under grants R56HL135425 and R01HL141773.

\section{Conflicts of Interest}

FG consults for Abbott, Amgen, Bayer, Janssen, Medtronic, and Novartis.

\section{Multimedia Appendix 1}

Questions in mobile health survey.

[DOCX File, 18 KB-Multimedia Appendix 1]

\section{Multimedia Appendix 2}

Ownership of mobile technology among participants interested in mobile health features.

[DOCX File, 52 KB-Multimedia Appendix 2]

\section{References}

1. Coronel R, de Groot JR, van Lieshout JJ. Defining heart failure. Cardiovasc Res 2001 Jun;50(3):419-422. [doi: 10.1016/s0008-6363(01)00284-x] [Medline: 11376615 ]

2. Jessup M, Abraham WT, Casey DE, Feldman AM, Francis GS, Ganiats TG, et al. 2009 focused update: ACCF/AHA guidelines for the diagnosis and management of heart failure in adults: a report of the american college of cardiology foundation/american heart association task force on practice guidelines: developed in collaboration with the international society for heart and lung transplantation. Circulation 2009 Apr 14;119(14):1977-2016. [doi: 10.1161/CIRCULATIONAHA.109.192064] [Medline: 19324967] 
3. Benjamin EJ, Virani SS, Callaway CW, Chamberlain AM, Chang AR, Cheng S, American Heart Association Council on Epidemiology and Prevention Statistics Committee and Stroke Statistics Subcommittee. Heart disease and stroke statistics-2018 update: a report from the American Heart Association. Circulation 2018 Mar 20;137(12):e67-492. [doi: 10.1161/CIR.0000000000000558] [Medline: 29386200]

4. Bui AL, Horwich TB, Fonarow GC. Epidemiology and risk profile of heart failure. Nat Rev Cardiol 2011 Jan;8(1):30-41 [FREE Full text] [doi: 10.1038/nrcardio.2010.165] [Medline: 21060326]

5. Heidenreich PA, Albert NM, Allen LA, Bluemke DA, Butler J, Fonarow GC, American Heart Association Advocacy Coordinating Committee, Council on Arteriosclerosis, Thrombosis and Vascular Biology, Council on Cardiovascular Radiology and Intervention, Council on Clinical Cardiology, Council on Epidemiology and Prevention, Stroke Council. Forecasting the impact of heart failure in the United States: a policy statement from the American Heart Association. Circ Heart Fail 2013 May;6(3):606-619 [FREE Full text] [doi: 10.1161/HHF.0b013e318291329a] [Medline: 23616602]

6. Ho KK, Pinsky JL, Kannel WB, Levy D. The epidemiology of heart failure: the Framingham study. J Am Coll Cardiol 1993 Oct;22(4 Suppl A):6A-13A [FREE Full text] [doi: 10.1016/0735-1097(93)90455-a] [Medline: 8376698]

7. Mosterd A, Hoes AW, de Bruyne MC, Deckers JW, Linker DT, Hofman A, et al. Prevalence of heart failure and left ventricular dysfunction in the general population; the Rotterdam study. Eur Heart J 1999 Mar;20(6):447-455. [doi: 10.1053/euhj.1998.1239] [Medline: 10213348]

8. Huffman MD, Berry JD, Ning H, Dyer AR, Garside DB, Cai X, et al. Lifetime risk for heart failure among white and black Americans: cardiovascular lifetime risk pooling project. J Am Coll Cardiol 2013 Apr 9;61(14):1510-1517 [FREE Full text] [doi: 10.1016/j.jacc.2013.01.022] [Medline: 23500287]

9. Evangelista LS, Shinnick MA. What do we know about adherence and self-care? J Cardiovasc Nurs 2008;23(3):250-257 [FREE Full text] [doi: 10.1097/01.JCN.0000317428.98844.4d] [Medline: 18437067]

10. Keenan PS, Normand ST, Lin Z, Drye EE, Bhat KR, Ross JS, et al. An administrative claims measure suitable for profiling hospital performance on the basis of 30-day all-cause readmission rates among patients with heart failure. Circ Cardiovasc Qual Outcomes 2008 Sep;1(1):29-37. [doi: 10.1161/CIRCOUTCOMES.108.802686] [Medline: 20031785]

11. Krumholz HM, Merrill AR, Schone EM, Schreiner GC, Chen J, Bradley EH, et al. Patterns of hospital performance in acute myocardial infarction and heart failure 30-day mortality and readmission. Circ Cardiovasc Qual Outcomes 2009 Sep;2(5):407-413. [doi: 10.1161/CIRCOUTCOMES.109.883256] [Medline: 20031870]

12. Krumholz HM, Parent EM, Tu N, Vaccarino V, Wang Y, Radford MJ, et al. Readmission after hospitalization for congestive heart failure among medicare beneficiaries. Arch Intern Med 1997 Jan 13;157(1):99-104. [doi: 10.1001/archinte.1997.00440220103013] [Medline: 8996046]

13. The Medicare Payment Advisory Commission. 2007. June 2007: Report to the Congress: Promoting Greater Efficiency in Medicine URL: http://www.medpac.gov/docs/default-source/reports/Jun07 EntireReport.pdf [accessed 2019-09-18]

14. Kumar S, Nilsen WJ, Abernethy A, Atienza A, Patrick K, Pavel M, et al. Mobile health technology evaluation: the mHealth evidence workshop. Am J Prev Med 2013 Aug;45(2):228-236 [FREE Full text] [doi: 10.1016/j.amepre.2013.03.017] [Medline: 23867031]

15. Steinhubl SR, Muse ED, Topol EJ. The emerging field of mobile health. Sci Transl Med 2015 Apr 15;7(283):283rv3 [FREE Full text] [doi: 10.1126/scitranslmed.aaa3487] [Medline: 25877894]

16. Creber RM, Maurer MS, Reading M, Hiraldo G, Hickey KT, Iribarren S. Review and analysis of existing mobile phone apps to support heart failure symptom monitoring and self-care management using the mobile application rating scale (MARS). JMIR Mhealth Uhealth 2016 Jun 14;4(2):e74 [FREE Full text] [doi: 10.2196/mhealth.5882] [Medline: 27302310]

17. Alharbi M, Straiton N, Gallagher R. Harnessing the potential of wearable activity trackers for heart failure self-care. Curr Heart Fail Rep 2017 Feb;14(1):23-29. [doi: 10.1007/s11897-017-0318-z] [Medline: 28181075]

18. Speier W, Dzubur E, Zide M, Shufelt C, Joung S, van Eyk JE, et al. Evaluating utility and compliance in a patient-based eHealth study using continuous-time heart rate and activity trackers. J Am Med Inform Assoc 2018 Oct 1;25(10):1386-1391 [FREE Full text] [doi: 10.1093/jamia/ocy067] [Medline: 29850807]

19. Criteria Committee of New York Heart Association. In: Dolgin M, editor. Nomenclature and Criteria for Diagnosis of Diseases of the Heart and Great Blood Vessels. Ninth Edition. Boston: Little, Brown \& Co; 1994.

20. Likert R. A technique for the measurement of attitudes. Arch Psychol 1932;22(140):5-55 [FREE Full text]

21. Rutten LJ, Davis T, Beckjord EB, Blake K, Moser RP, Hesse BW. Picking up the pace: changes in method and frame for the health information national trends survey (2011-2014). J Health Commun 2012;17(8):979-989 [FREE Full text] [doi: 10.1080/10810730.2012.700998] [Medline: 23020763]

22. Behlouli H, Feldman DE, Ducharme A, Frenette M, Giannetti N, Grondin F, et al. Identifying relative cut-off scores with neural networks for interpretation of the Minnesota Living with Heart Failure questionnaire. Conf Proc IEEE Eng Med Biol Soc 2009;2009:6242-6246. [doi: 10.1109/IEMBS.2009.5334659] [Medline: 19965089]

23. Riegel B, Lee CS, Dickson VV, Carlson B. An update on the self-care of heart failure index. J Cardiovasc Nurs 2009;24(6):485-497 [FREE Full text] [doi: 10.1097/JCN.0b013e3181b4baa0] [Medline: 19786884]

24. Spertus JA, Jones P, McDonell M, Fan V, Fihn SD. Health status predicts long-term outcome in outpatients with coronary disease. Circulation 2002 Jul 2;106(1):43-49. [doi: 10.1161/01.cir.0000020688.24874.90] [Medline: 12093768] 
25. Green CP, Porter CB, Bresnahan DR, Spertus JA. Development and evaluation of the Kansas City Cardiomyopathy questionnaire: a new health status measure for heart failure. J Am Coll Cardiol 2000 Apr;35(5):1245-1255 [FREE Full text] [doi: $\underline{10.1016 / \mathrm{s} 0735-1097(00) 00531-3}$ ] [Medline: $\underline{10758967]}$

26. Broderick JE, DeWitt EM, Rothrock N, Crane PK, Forrest CB. Advances in patient-reported outcomes: the NIH PROMIS(®) measures. EGEMS (Wash DC) 2013;1(1):1015 [FREE Full text] [doi: 10.13063/2327-9214.1015] [Medline: 25848562]

27. Hays RD, Bjorner JB, Revicki DA, Spritzer KL, Cella D. Development of physical and mental health summary scores from the patient-reported outcomes measurement information system (PROMIS) global items. Qual Life Res 2009 Sep;18(7):873-880 [FRE Full text] [doi: 10.1007/s11136-009-9496-9] [Medline: 19543809]

28. Downey RG, King C. Missing data in Likert ratings: a comparison of replacement methods. J Gen Psychol 1998 Apr;125(2):175-191. [doi: 10.1080/00221309809595542] [Medline: 9935342]

29. Riegel B, Moser DK, Glaser D, Carlson B, Deaton C, Armola R, et al. The Minnesota Living With Heart Failure questionnaire: sensitivity to differences and responsiveness to intervention intensity in a clinical population. Nurs Res 2002;51(4):209-218. [doi: 10.1097/00006199-200207000-00001] [Medline: 12131233]

30. Melenhorst A, Rogers WA, Bouwhuis DG. Older adults' motivated choice for technological innovation: evidence for benefit-driven selectivity. Psychol Aging 2006 Mar;21(1):190-195. [doi: 10.1037/0882-7974.21.1.190] [Medline: 16594804]

31. Mitzner TL, Boron JB, Fausset CB, Adams AE, Charness N, Czaja SJ, et al. Older adults talk technology: technology usage and attitudes. Comput Human Behav 2010 Nov 1;26(6):1710-1721 [FREE Full text] [doi: 10.1016/j.chb.2010.06.020] [Medline: 20967133]

32. Melenhorst AS, Rogers WA, Caylor EC. The Use of Communication Technologies by Older Adults: Exploring the Benefits from the User's Perspective. In: Proceedings of the Human Factors and Ergonomics Society Annual Meeting. 2001 Presented at: HFES'01; October 8-12, 2001; Minneapolis, Minnesota, USA p. 221-225. [doi: 10.1177/154193120104500305]

33. Czaja SJ, Charness N, Fisk AD, Hertzog C, Nair SN, Rogers WA, et al. Factors predicting the use of technology: findings from the Center for Research and Education on Aging and Technology Enhancement (CREATE). Psychol Aging 2006 Jun;21(2):333-352 [FREE Full text] [doi: 10.1037/0882-7974.21.2.333] [Medline: 16768579]

34. de Jong MJ, Chung ML, Wu J, Riegel B, Rayens MK, Moser DK. Linkages between anxiety and outcomes in heart failure. Heart Lung 2011;40(5):393-404 [FREE Full text] [doi: 10.1016/j.hrtlng.2011.02.002] [Medline: 21453974]

\author{
Abbreviations \\ EF: ejection fraction \\ HRQOL: health-related quality of life \\ IQR: interquartile range \\ KCCQ: Kansas City Cardiomyopathy Questionnaire \\ mHealth: mobile health \\ MLHFQ: Minnesota Living with Heart Failure Questionnaire \\ NYHA: New York Heart Association \\ PRO: patient-reported outcome \\ PROMIS: Patient-Reported Outcomes Measurement Information System \\ SAQ: Seattle Angina Questionnaire \\ SCHFI: Self-Care of Heart Failure Index \\ SF: short form
}

\author{
Edited by G Eysenbach; submitted 18.04.19; peer-reviewed by A Miranda, A Gomez-Rexrode, E Muse; comments to author 06.06.19; \\ revised version received 15.07.19; accepted 19.07.19; published 29.10.19 \\ Please cite as: \\ Sohn A, Speier W, Lan E, Aoki K, Fonarow G, Ong M, Arnold C \\ Assessment of Heart Failure Patients' Interest in Mobile Health Apps for Self-Care: Survey Study \\ JMIR Cardio 2019;3(2):e14332 \\ URL: https://cardio.jmir.org/2019/2/e14332 \\ doi: $10.2196 / 14332$ \\ PMID: 31758788
}

(C)Albert Sohn, William Speier, Esther Lan, Kymberly Aoki, Gregg Fonarow, Michael Ong, Corey Arnold. Originally published in JMIR Cardio (http://cardio.jmir.org), 29.10.2019. This is an open-access article distributed under the terms of the Creative Commons Attribution License (https://creativecommons.org/licenses/by/4.0/), which permits unrestricted use, distribution, and reproduction in any medium, provided the original work, first published in JMIR Cardio, is properly cited. The complete 
bibliographic information, a link to the original publication on http://cardio.jmir.org, as well as this copyright and license information must be included. 